\title{
Gentilicios en la prensa de Castilla y León: ¿innovación o conservadurismo?
}

\author{
J. AGUSTÍN TORIJANO \\ MIGUEL SÁNCHEZ IBÁÑEZ \\ Grupo NeoUSAL, Universidad de Salamanca
}

\section{INTRODUCCIÓN}

La indiscutible vinculación del estudio de los gentilicios a diferentes ámbitos de la Lexicografía está fuera de toda duda, y puesta de manifiesto desde hace mucho tiempo en innumerables trabajos llevados a cabo, tanto por grupos de investigadores generales (ámbitos de la Filología, la Sociolingüística, la Etnolingüística, etc.), como por equipos específicos del estudio de los gentilicios ${ }^{1}$.

Aunque en su origen los gentilicios eran los nombres de familia o de linaje (la voz procede del latín gentilitius y este, a su vez de gens, el epíteto usado en el Imperio Romano para denominar a un grupo social formado por varias familias que compartían el cognomen o apellido), en la actualidad este tipo de palabras son, principalmente, las que se emplean para describir la procedencia geográfica de un sujeto. Su presencia en el lenguaje coloquial y cotidiano, así como en los medios de comunicación, es constante y recogen en su naturaleza una gran cantidad de información lingüística.

Por un lado, la variedad de recursos formativos presentes en su constitución como unidades léxicas, evidenciada por una gran diversidad de afijos, soluciones compositivas y derivaciones que se utilizan en su formación.

Por el otro, el fuerte peso de factores históricos y sociales a la hora de acuñar una unidad de estas características, que refleja la importancia que tiene denominar a los procedentes de un lugar de una u otra manera, ya que la solución que finalmente asiente se convertirá en una suerte de trasunto de ciertos aspectos (y no de otros) del lugar en cuestión. De la suma de todas estas variables surgen unas unidades léxicas marcadas por su alto grado de variabilidad, por la imposibilidad de establecer unas reglas forma-

* El presente artículo debe su origen, con otros trabajos similares, a los resultados de la investigación llevada a cabo por el Grupo NeoUSAL (www.neousal.usal.es), en el marco del Proyecto titulado «Mecanismos de generación neológica y actualización léxica del español a través del estudio de la prensa castellanoleonesa», con número de referencia SA030A10-1, y concedido por la Dirección General de Universidades e Investigación, de la Junta de Castilla y León.

${ }^{1}$ Como pueden ser los trabajos de Graçia Maria Rio-Torto o el Grupo GentiDB de Universidad de La Laguna, por citar uno de los más activos, o por la mera presencia de tales términos en las obras lexicográficas, al uso y especializadas. 
tivas estables que permitan su sistematización morfológica, y por la alta carga semántica que pueden contener.

Atendiendo a todos estos factores, el presente artículo pretende describir y agrupar este tipo de unidades de acuerdo con los datos encontrados en una comunidad lingüística concreta (Castilla y León), tomando como base un corpus determinado (una selección de ejemplares de prensa escrita publicados para dicha comunidad lingüística) y atendiendo para ello a los gentilicios propiamente dichos (esto es, a adjetivos que denotan procedencia geográfica) y a otras unidades, eminentemente adjetivas, que se utilizan para hacer referencia a realidades fuertemente ligadas a enclaves geográficos concretos.

Para conseguirlo, el estudio se centra en varios puntos: por un lado, reflexiona sobre la caracterización de los gentilicios y la naturaleza de las variantes que cada uno de ellos puede tener. Por otro, analiza desde distintas perspectivas la evolución y el uso de estas unidades. Por último, toma como marco de trabajo las conclusiones extraídas de los dos apartados anteriores, describe los resultados hallados en el rastreo de gentilicios y del tipo de adjetivos ya mencionados en un conjunto de periódicos del ámbito castellanoleonés, y los interpreta con el fin de llegar a una conclusión plausible sobre el peso del uso de gentilicios en la innovación lingüística de la prensa castellanoleonesa.

\section{GENTILICIO: CARACTERIZACIÓN Y VARIANTES}

\subsection{Caracterización semántica}

Podría afirmarse que el término gentilicio se halla a medio camino entre el tecnicismo lingüístico y las voces de conocimiento general, mucho más que otras relacionadas epistemológicamente con los vínculos que se establecen entre la lengua y los lugares que esta denota (topónimo, hidrónimo, orónimo, etc.) o donde se habla (isoglosa, diglosia, horiometría, etc.). Esta mayor proximidad a la lengua común puede deberse a diferentes factores, entre los que podemos destacar tres:

1. Su ya mencionado origen latino, frente al origen griego de los otros tecnicismos y su presencia en español, recogida desde hace más de dos siglos (1803).

2. La existencia del término en otros ámbitos, como pueda ser el Derecho, formando parte de expresiones del tipo campo gentilicio ${ }^{2}$, o la recogida por el DRAE retracto gentilicio ${ }^{3}$.

3. El campo semántico al que pertenece, toda vez que se trata de un sustantivo/adjetivo que habla de la gente, de los pueblos donde habitan, de sus identidades colectivas, etc.

Ahora bien, centrándonos en el valor semántico del término — de la forma nos ocuparemos más adelante_- los diccionarios generales — como suele ser más habitual de lo deseable - muestran ciertas diferencias que, sin llegar a ser forzosamente contradic-

${ }^{2}$ Ager gentilicius: Se considera la propiedad de una gens antes de dividirlo entre las familias que la constituían. Campo gentilicio (Diccionario Jurídico en www.DRLeyes.com).

${ }^{3}$ retracto de sangre, o retracto gentilicio. 1. $\mathrm{m}$. Der. retracto concedido por las leyes en razón de parentesco, para recuperar fincas de abolengo. 
torias, no coinciden plenamente en sus definiciones. Así, por ejemplo, y en algo aparentemente superficial como es el número de acepciones que recogen los diccionarios de la voz que nos ocupa, mientras el $D R A E$ (versión en línea) ofrece tres acepciones, el Diccionario de Uso de Español de María Moliner (en formato CD) recoge dos, y el Diccionario de Uso del Español de América y España VOX y el CLAVE (ambas también en versión $C D$ ) las reducen a una. Del mismo modo, las propias definiciones hacen referencia a aspectos diferentes, como se observa en una primera lectura de las correspondientes acepciones:

$D R A E$ : «adj. Perteneciente o relativo a las gentes o naciones.; 2. adj. Perteneciente o relativo al linaje o familia y 3. $\mathrm{m}$. Gram. adjetivo gentilicio», que remite a la siguiente definición: «m. Gram. adjetivo que denota la procedencia geográfica de las personas o su nacionalidad; p. ej., castellano, madrileño, andaluz, peruano, bonaerense».

DUEMM: «adj. De cierta gente (nación). 5adj. y n. m. Ling. Se aplica particularmente a los nombres y adjetivos que expresan *naturaleza o nacionalidad; como andaluz, castellano o barcelonés».

$V O X:$ «[nombre, adjetivo] Que expresa el origen geográfico o racial: ej. 'peruano', ‘japonés' y 'español' son adjetivos gentilicios».

CLAVE: «Adjetivo o sustantivo masculino Referido a un adjetivo o a un sustantivo, que expresa el origen o la patria: 'Abulense' es el gentilicio que se aplica a los oriundos de 'Ávila'».

Analizando someramente el contenido de cada uno de los artículos lexicográficos, se observan estas diferencias conceptuales:

\begin{tabular}{|l|l|l|}
\hline & Término 1 & Término 2 \\
\hline DRAE & procedencia geográfica & nacionalidad \\
\hline DUEMM & naturaleza & nacionalidad \\
\hline VOX & origen geográfico & origen racial \\
\hline CLAVE & origen & patria \\
\hline
\end{tabular}

Figura 1. Tabla de diferencias conceptuales en las distintas definiciones de gentilicio en diccionarios generales.

Profundizando un poco más en las definiciones en obras especializadas, parece que las diferencias, lejos de desaparecer, aumentan y matizan aspectos diversos. Pese a que se trata de una obra ya clásica pero con continuas reediciones (2008 es, de momento, la última), el Diccionario de términos filológicos, de F. Lázaro Carreter, define así el término como un «adjetivo o sustantivo que denota el origen, raza o patria: catalán, polaco, judío».

Por su parte, el Glosario Electrónico de Términos Lingüísticos lo define de la siguiente manera:

gentilicio: un sustantivo, frase nominal [2], o adjetivo que se usa para nombrar un pueblo, grupo étnico, o grupo nacional, o identificar miembro(s) de tales grupos. 
Por ejemplo: «Mexicano» es un gentilicio. Compárese con topónimo. [inglés: ethnonym].

Si esquematizamos las dos definiciones especializadas, obtendremos que, a diferencia de las anteriores, los tres conceptos repartidos en los diferentes diccionarios generales se combinan, por lo que parece evidente que son más completas y que recogen todos los valores del gentilicio.

\begin{tabular}{|l|l|l|l|}
\hline & Término 1 & Término 2 & Término 3 \\
\hline DTF & origen & raza & patria \\
\hline GETL & pueblo & grupo étnico & grupo nacional \\
\hline
\end{tabular}

Figura 2. Tabla de diferencias conceptuales en las distintas definiciones de gentilicio en diccionarios especializados

Se trata, por tanto, y pese a las diferencias, de un término que alude a los orígenes geográficos y étnicos (en sentido amplio), quizá los dos soportes semánticos sobre los que deba asentarse el concepto, dado que las nociones de patria o país reducirían los gentilicios a los alusivos a los macrotopónimos (España, Rusia, Cabo Verde o Canadá), mientras que al hablar de «orígenes geográficos» podemos aplicar el adjetivo o sustantivo gentilicio no solo hasta la población más pequeña, sino también a zonas o regiones, no necesariamente constituidas políticamente en provincias, comunidades autónomas o ciudades. Serían casos como maragato, charro, amazónico, patagón o subsahariano, por citar solo algunos.

\subsection{Caracterización formal}

La caracterización morfológica más representativa y casi exclusiva de los gentilicios es, sin lugar a dudas, el llamativo desequilibrio entre la enorme diversidad de desinencias posibles y, quizá por ello, la escasa productividad de muchas de esas formas de derivación. Como afirma F. Rainer (1999), estos adjetivos deonomásticos de lugar se caracterizan por la baja (o nula) productividad de algunos de los sufijos que los forman, debido, sin duda, a que muchos son específicos para esta función, y apenas tienen valor formativo fuera de este ámbito. Piénsese, por ejemplo, en -eño o en -í. Como veremos más abajo, la enorme variedad de sufijos es, por tanto, inversamente proporcional, a la escasa rentabilidad en el sistema.

En efecto, de entre todos los grupos funcionales de sufijos en español, es, sin duda, el referido a los gentilicios (y afines) el más productivo de todos ellos. En palabras de J. Pena (1999),

Para formar nombres y adjetivos gentilicios, la derivación dispone de una amplia gama de sufijos (malagu-eño, orens-ano, Boston-iano, chil-eno, alicant-ino, coruñés, luc-ense, etc.). Se trata en todos estos casos, de sufijos sinónimos o equifuncionales en distribución potencialmente libre o impredecible, que en algunas ocasiones, como en la de los gentilicios, pueden prácticamente agruparse en conjuntos de alomorfos: de un lado -ense y -és y, de otro, -ano, -iano, -eno, -ino, etc. 
Del mismo modo, y aplicado a los llamados adjetivos étnicos del portugués, G. M. Rio-Torto (2008) afirma:

No século XVIII documentam-se alguns gentílicos, denotando «que provém de x», como mineiro, brasileiro, campineiro (Viaro 2007). Segundo Cunha (1997), o gentílico brasileiro apenas se documenta no século XIX e mineiro já no século XVII. Importa mencionar que desde sempre em português o sufixo -eir concorreu com muitos outros sufixos também portadores de valor gentílico, pátrio ou étnico, razão pela qual ao longo dos séculos viria a revelar-se menos aproveitado para tais funções. Recorde-se que, de acordo com Viaro (2002), nas 420 Cantigas de Santa Maria, compostas no último quartel do séc. XIII (1270-1282), o sufixo predominante para esta função é -ão, -ãa (v.g. perssião, romão, africão, aleimãa, aldeão, vilão). Os demais étnicos são portadores de -es (burgues, genoes, frances, marques, leones), não ocorrendo formas com o sufixo -ense. O sufixo -en- está representado apenas no adjectivo damasceno.

Una mera comparación entre tales grupos, en cualquiera de las dos lenguas, arroja resultados incontestables acerca del enorme potencial productivo y de diversificación de este grupo funcional.

A modo de ejemplo, observemos que, frente a grupos del tipo «profesión», para el que se seleccionan sufijos del tipo -ario/-aria, -ista o -or/-ora (bibliotecario, electricista o profesor) o -ente para los cargos (presidente, gerente, agente), etc., el grupo funcional de los sufijos para el tipo «gentilicio» puede seleccionar una nómina de en torno a los veinticinco morfemas, lo cual revela una idiosincrasia muy particular, debido, básicamente a tres razones:

a) La dificultad de sistematizar el proceso de derivación a partir de las correspondientes formas primitivas ante la inexistencia de un supuesto patrón común que debería producir el mismo tipo de sufijos. Son evidentes los casos de Madrid vs. Valladolid, Valencia vs. Palencia, o Toledo vs. Oviedo, que no generan los mismos derivados, pese a que, aparentemente, el punto de partida sea el mismo.

b) La dispersión, muchas veces debida a razones culturales, mostrada en gentilicios divergentes a partir, no ya del mismo patrón, sino del mismo topónimo. A este respecto, debe recordarse que de poblaciones denominadas Santiago pueden encontrarse, al menos, nueve gentilicios diferentes: por una parte, los que llamaremos gentilicios propios, es decir, santiagueño -ña (de la Provincia de Santiago del Estero (Argentina) o de su capital Santiago del Estero), santiaguino -na (de Santiago de Chile), santiaguero -ra (de Santiago de Cuba), santiagués -esa (de Santiago de la Puebla, en Salamanca, España) y, por otra, los que llamaremos gentilicios impropios, es decir, compostelano -na (de Santiago de Compostela, España), caleño -ña (de Santiago de Cali, en Colombia), caraqueño -ña (de Santiago de León de Caracas, Venezuela), guayaquileño - ̃̃a (de Santiago de Guayaquil, Ecuador) o surcano -na (de Santiago de Surco, en Lima, Perú). Este fenómeno se repite con una gran variedad de topónimos, como ocurre también con las poblaciones denominadas Palma, La Palma, Las Palmas, etc., para las cuales la lengua selecciona, entre otros, palmero -ra, palmense, palmesano -ana, etc., como ocurre con Santander (santanderino -na frente a santandereano -na, según sea referido a España o a Colombia).

c) La existencia de dos (o más) gentilicios referidos al mismo topónimo que conviven en un mismo momento, aunque con valores socioculturales o pragmáticos diferentes. En muchas ocasiones, no hay la misma referencia exacta entre el gentilicio ac- 
tual y el histórico o el popular, al tratarse de gentilicios que pueden no pertenecer exactamente al territorio actual por la evolución de la deriva histórica, pero gozan de una enorme productividad, en ocasiones por razones de estilo (evitar repeticiones), intención humorística, connotaciones históricas, etc. Se trata de casos sobradamente conocidos del tipo alicantino/lucentino; pacense/badajocense; menorquín/menorqués/minoricense; santanderino/cántabro; portugués/lusitano; griego/heleno; francés/galo, y hasta los claramente incorrectos de brasileño/carioca; mexicano/azteca o israelí/israelita/hebreo, por citar solo algunos casos.

\section{APROXIMACIÓN DIACRÓNICA Y SINCRÓNICA A LOS GENTILICIOS}

\subsection{Aproximación diacrónica}

Aunque incluso una mera aproximación diacrónica ocuparía un espacio inmensamente superior a este trabajo, dejemos anotado que la enorme variedad morfológica de los gentilicios en la actualidad no es — no podría serlo - un fenómeno reciente, ni tan siquiera circunscrito a la existencia propia de nuestras lenguas desde un punto de visto sincrónico como las conocemos en la actualidad.

En efecto, la variabilidad de las derivaciones morfológicas fueron ya objeto de estudio para un buen número de gramáticos y retóricos latinos, conscientes, sin duda, de la potencialidad de una lengua que se extendía tanto en el espacio como en el tiempo, lo cual - como sigue ocurriendo en la actualidad con el inglés, el español y el portugués - suele ser razón suficiente para constatar la llamada variación lingüística de una lengua más o menos común.

Así, por ejemplo, el retórico calagurritano Quintiliano, ya en el año 95 de nuestra era, mostraba su preocupación por las diferencias de género de los sustantivos y por la fuerza (tantas veces engañosa) de la analogía (tratada con exhaustividad en los estudios de morfología de F. Rainer). El autor de las Institutio Oratoria reflexionaba sobre las dudas que surgen al hablar, y aconsejaba, en estos casos, un método doble: por una parte, comparar el término inseguro (por su terminación, por el género gramatical, por la declinación, etc.) con otro que se tenga por seguro para fijar la certeza del primero, o, en otros casos, aplicar algún cambio al término en duda, como puede ser añadirle el diminutivo.

De este modo, si un estudiante o un hablante cualquiera duda, por ejemplo, sobre el género de fünis ('maroma, cable'), debe compararlo con un término similar, por ejemplo panis ('pan'), para deducir que el término inseguro es masculino, porque el segundo lo es. La otra posibilidad, apunta el calagurritano, podría ser someterlo a su diminutivo, füniculus, para comprobar, que, efectivamente, se trata de un sustantivo masculino.

Este método doble de analogía o de derivación, ciertamente útil en muchos casos, entra, sin embargo, en conflicto en numerosas ocasiones, como argumenta más adelante el propio autor, cuando afirma que «deberíamos tener presente que no se puede aplicar a todas las palabras el método de la analogía, porque se contradice a sí misma en muchísimos casos»».

Y así compara lepus ('liebre') con lupus ('lobo'), y constata que la primera voz tiene género epiceno, y puede designar ejemplares de uno u otro sexo, tanto en latín como en español, mientras que la segunda, por mucho que termine igual que la primera, es 
solo masculina, al lado de lupa, necesaria para designar el femenino. Si esto sucede con el método para determinar el género, lo mismo ocurre para los casos de duda del genitivo, al que se refería más arriba, y lo ejemplifica con los sustantivos terminados en -es, que pueden presentar varias terminaciones de genitivo, «pero jamás terminan en la sílaba -ris» y, sin embargo, se pregunta «¿cómo Ceres obliga [sic] a que se diga Cereris?». Y aún más, se cuestiona la validez del método sobre aquellas palabras que tienen por igual su forma y evolucionan de forma diferente, como, por ejemplo, Alba que hace albanos y albenses y volo ('querer'), que genera volui y volavi ('quise' y 'he querido'), pero cado ('caer') hace cecidi.

Concluyamos, como hace el propio Quintiliano, otorgándole a la analogía única y exclusivamente una función delimitada, nunca absoluta, «pues, cuando fueron creados los hombres, la Analogía [sic], bajada del cielo, no les dio el modelo del lenguaje, sino que fue inventada después de que ellos empezaran a hablar, pues [...] no se fundamenta en ella una normativa racional, sino en el ejemplo y no existe una ley del lenguaje, sino una observación del mismo, de suerte que ninguna otra cosa haya creado la analogía a no ser la costumbre».

Es, precisamente, esta idea la que parece prevalecer al establecer un estudio sobre el comportamiento de los gentilicios en español, dado que el posible método de la analogía tan solo aporta algunas soluciones a la hora de producir tales adjetivos, de forma que cifrar todo a la comparación es condenar al error la producción de un paradigma que sirva de modelo para tales derivaciones.

\subsection{Aproximación sincrónica comparativa}

Como apuntábamos más arriba, el comportamiento de los gentilicios en latín, descrito por Quintiliano, ha seguido ofreciendo las mismas características en las lenguas romances, de tal forma que constituye el grupo de derivación más diverso y fructífero de cuantos componen el paradigma morfosintáctico del sustantivo/adjetivo. Sin embargo, esto no es así (ni tiene por qué serlo, por otra parte) en otras lenguas, como ocurre en inglés, tomado como referencia de lengua europea no latina. Así se demuestra en el análisis de los gentilicios mayores correspondientes a más de 100 macrotopónimos (de países/continentes) en portugués, inglés y alemán del que fácilmente se deduce la enorme diferencia entre los comportamientos de una y otra lengua, y, por extensión, de una y otra familia de lenguas.

En los casos en los que existen dos adjetivos en inglés, el segundo se refiere específicamente al gentilicio, otro caso de falta de armonización, dado que, en la inmensa mayoría de los casos, es suficiente con el adjetivo general. Debe notarse que esta duplicidad solo existe en las voces terminadas en -ish y en la mitad de las voces no sistematizadas.

Al comparar las soluciones de otra lengua romance como el portugués con una que no lo es, como es el caso del inglés (o con el alemán), observamos que los parámetros de diversidad y de falta de analogía son muy similares en ambas lenguas neolatinas. Evidentemente, Quintiliano no podía prever este comportamiento futuro de las lenguas, pero parece innegable cierta similitud entre lo que él advertía para su lengua materna y lo que la lógica evolución de las lenguas romances ha producido y sigue produciendo. 
Así también se pone de manifiesto en todos los estudios sobre el tema en la bibliografía en portugués. Obsérvese el ejemplo de Castelo Branco, tomado de la página web Portal da Língua Portuguesa:

Existem várias formas de criar gentílicos. Os mais comuns são os formados por sufixos como -ês (português), -ense (macaense) e -ano (americano). Porém, a formação dos gentílicos nem sempre consiste na mera junção de um sufixo à base do topónimo (nome de um sítio ou local), existindo processos mais complexos, por vezes com justificações etimológicas ou históricas: por exemplo, o gentílico de Castelo Branco é albicastrense e não castelo-branquês, castelo-branquense ou castelo-brancano.

\section{EL GENTILICIO Y LOS ADJETIVOS RELACIONADOS CON REALIDADES GEOGRÁFI- CAS: SU USO EN LA PRENSA DE CASTILLA Y LEÓN}

Hasta este punto hemos pretendido clarificar el concepto de gentilicio, recopilar las diferentes definiciones que podemos encontrar y describir someramente la problemática que entraña sistematizar su descripción y estudio. Esta parte del artículo tiene como objetivo concretar toda esta información en un contexto específico (prensa castellanoleonesa) y con un fin determinado: clarificar en qué medida es marca de conservadurismo lingüístico el uso de este tipo de unidades en los medios de comunicación escritos de esa comunidad.

\subsection{Metodología y desarrollo del estudio}

Como se ha indicado previamente (vid. n.1), los datos presentados a continuación se han obtenido de un estudio realizado por el grupo NeoUSAL dentro de su Proyecto de Investigación «Mecanismos de generación neológica y actualización léxica del español a través del estudio de la prensa castellanoleonesa». Ha sido desarrollado en el seno del Observatorio de Neología (OBNEO), del Institut Universitari de Lingüística Aplicada (IULA) de la Universitat Pompeu Fabra (Barcelona), desde donde se coordinan trabajos de varios grupos de investigación relacionados con la neología y la creación léxica. El objetivo del proyecto, como su nombre indica, es estudiar la neología léxica del español a partir de textos aparecidos en la prensa regional de Castilla y León. Para conseguirlo, se realizó una selección de los principales periódicos de la comunidad ${ }^{4}$, de los que trataron automáticamente dos números por mes durante dos años ${ }^{5}$.

Dicho tratamiento consistió en el filtrado de ese corpus y el contraste automático del conjunto de palabras que los constituían con los lemarios de dos diccionarios: el Diccionario de la Real Academia Española ${ }^{6}$ (edición 2001) y el Diccionario de Uso

\footnotetext{
${ }^{4}$ Los periódicos seleccionados fueron: La Opinión de Zamora, El Norte de Castilla, El Día de Valladolid, El Mundo (Edición Castilla y León), El Adelantado de Segovia, Diario Palentino, Diario de León, La Gaceta de Salamanca y El Diario de Ávila.

${ }^{5}$ El tratamiento se realizó gracias a las herramientas desarrolladas para tal fin por el Observatorio de Neología del IULA (OBNEO), de la Universitat Pompeu Fabra.

${ }^{6}$ Existen trabajos recientes acerca del tratamiento lexicográfico de los gentilicios por parte del DRAE, como el de Pérez Vigaray y Herrera Santana (2013), pero en nuestro caso, como ya hemos dicho, la relevancia de las unidades analizadas se basa precisamente en su no inclusión en determinados diccionarios.
} 
del español de América y España (2002). La lista de unidades que no aparecían en ninguno de los dos constituyó un primer elenco de candidatos a neologismos, que fueron analizados posteriormente por los miembros del grupo NEOusal. En primer lugar, realizaron un segundo filtrado manual que permitió desechar unidades no neológicas que se escapan a la exclusión por criterio lexicográfico ${ }^{7}$, como pueden ser los nombres propios, las unidades con errores tipográficos o los adjetivos con sufijaciones aumentativas o diminutivas que no estén lexicalizadas. Para completar la selección de unidades por estudiar, también se realizaron varias extracciones manuales por parte de los miembros del grupo, con el fin de encontrar y analizar neología semántica y fraseológica, que pasa inadvertida en el filtro de los diccionarios

Las unidades que superaron el filtrado automático y el manual se agruparon en tres grupos diferenciados: préstamos, unidades estrechamente ligadas a realidades geográficas concretas (ya fueran gentilicios u otro tipo de adjetivos) y aquellas creadas con recursos de formación léxica propios. Nos parecieron, por su recurrencia y sus características, los tres tipos de unidades léxicas en los que a priori se podría encontrar más innovación léxica, lo que nos condujo a pensar que podían servir de parámetro para evaluar si Castilla y León, como comunidad lingüística, es conservadora o no.

El grupo de unidades recogidas que nos ocupa en este artículo es el de los gentilicios y unidades relativas a realidades geográficas. Conviene aclarar que la inmensa mayoría de estas unidades no son neológicas, pero el criterio lexicográfico clave en el proceso de detección nos permite acceder a ellas, ya que la mayoría no aparece en los diccionarios utilizados para el análisis. En otras palabras, se podría decir que al intentar detectar nuevas unidades nos topamos con un conjunto de palabras que, si bien no encajaban en nuestro propósito inicial, sí que podían aportarnos información relevante, por lo que consideramos significativo dedicarle una parte del estudio. Tras observar los contextos en los que se utilizaban elaboramos una clasificación de todas las unidades encontradas que hacían referencia, de una u otra manera, a un ámbito geográfico. Así, establecimos cuatro grupos de unidades:

- Gentilicios propiamente dichos: Este grupo engloba a las unidades que aparecieron en contextos meramente geográficos. Observamos que había una prevalencia significativa de composición ad hoc, mediante el uso de guiones, creada para transmitir una información concreta en una noticia determinada («la cultura catalano-valenciano-balear...», «serbo-español» «sahelo-saharaui»). Del mismo modo, y al contrario de lo que sucede en los otros tres grupos, la prefijación tenía un peso específico y relevante en el proceso de formación de unidades («norcaucásico»). De las 142 unidades recogidas, 89 (el 63\%) eran referentes a contextos geográficos castellanoleoneses.

${ }^{7}$ El criterio lexicográfico es uno de los que, tradicionalmente, más se ha utilizado a la hora de determinar la naturaleza neológica de las unidades léxicas, al presuponer que una unidad tiene más probabilidades de ser neológica si no se encuentra incluida en un diccionario, ya que eso demostraría, en principio, su reciente aparición. Si entendemos que los diccionarios recogen la parte de la lengua más asentada y estable, es fácil concluir que el hecho de que una palabra no esté incluida en ellos puede deberse a esa inestabilidad, ya sea formal, semántica o pragmática. 
- Adjetivos relacionados con entidades deportivas y sus seguidores: En este grupo se encuentran las unidades referentes únicamente a contextos deportivos. En la mayoría de los casos, esa especialización temática se debía más a una ausencia de contextos de otro tipo que al hecho de que las unidades estuvieran formadas específicamente para hacer referencia a informaciones de esta índole, como podemos observar en ejemplos como «Siguieron los visitantes poniendo en problemas al conjunto astudillano», donde vemos cómo el adjetivo astudillano, que hace referencia a los naturales de Astudillo (Palencia), se usa para designar al equipo de fútbol de la localidad, y su inclusión en este grupo se debe a no haber encontrado contextos relacionados con contextos no deportivos. Con todo, observamos dobletes interesantes ${ }^{8}$, como el venteño / ventabañense o el torrejonero / torrejonense, en los que una de las unidades hace referencia al equipo de fútbol y la otra al natural del municipio, lo que implicaría una cierta especialización sufijal ( «El colectivo, con sede en la estación venteña, está ahora mismo inmerso en un doble trabajo: la celebración del 150 aniversario de la llegada del ferrocarril a Venta de Banos y la puesta en marcha, de nuevo, de los viajes del tren turístico Camino de Santiago» y «Pero llegó el segundo cuarto y con él volvieron nuevamente los fantasmas de otros encuentros para los ventabañenses, que se estrellaban contra la dura defensa palentina, que cerró su zona para dejar en este periodo en ocho puntos a los locales»). Este grupo está compuesto por 28 unidades, de las que 15 (el $53 \%$ ) están vinculadas con Castilla y León.

- Gentilicios usados en contextos deportivos: Este grupo está formado por todas las unidades de las que se encontraron contextos tanto deportivos como geográficos. Observamos que el recurso principal de formación es la sufijación («el centrocampista del conjunto granjeño», «se han presentado los actos de la Semana santa granjeña»), pero el dato más relevante que se puede extraer de las unidades que engloba este grupo es que todas hacen referencia a lugares de Castilla y León.

- Casos especiales: El cuarto grupo sería un hipotético desglose del segundo, que englobaría a todas las unidades aparecidas en contexto deportivo pero referentes a otros elementos culturales relacionados con el lugar geográfico y el equipo en cuestión, como por ejemplo al nombre del equipo («ademarista», «recreativista»), a los colores de la equipación («rossonero», «blanquivioleta») o a los seguidores («gunner»). Es un grupo muy heterogéneo, en el que observamos una alta prevalencia de préstamos y extranjerismos, así como un número significativo de unidades marcadas tipográficamente, principalmente con comillas o cursiva, como se puede ver en los ejemplos «final feliz "rojillo"» o «Sin embargo, y pese a la superioridad manifiesta de la "canarinha", los dos primeros goles llegaron a balón parado». Es obvio que no estamos frente a unidades que se puedan considerar gentilicios, puesto que en ningún caso derivan de topónimos, pero la facilidad con la que remiten a enclaves geográficos concretos, así como su uso continuado en los textos seleccionados, nos hacen pensar en la utilidad de asociar su estudio con el de los gentilicios propiamente dichos, debido a la similitud semántica entre ambos tipos de unidades y a la variedad de opciones derivativas que presentan las unidades englobadas en este apartado.

\footnotetext{
${ }^{8}$ En realidad, la existencia de estos dobletes refuerza el concepto de «alogentilicio» defendido por García Delgado (2012).
} 


\begin{tabular}{|l|l|l|l|l|}
\hline & \multicolumn{1}{|c|}{ Gentilicios } & \multicolumn{1}{|c|}{ Deportivos } & \multicolumn{1}{|c|}{$\begin{array}{c}\text { Gentilicios } \\
\text { yeportivos }\end{array}$} & \multicolumn{1}{c|}{$\begin{array}{c}\text { Casos } \\
\text { especiales }\end{array}$} \\
\hline -ano, -ana & $\begin{array}{l}\mathbf{4 3} \text { (cuellarano, } \\
\text {-na) }\end{array}$ & & & \\
\hline$-e ́ s,-e s a$ & & $\begin{array}{l}6 \text { (monzonés, } \\
\text {-esa) }\end{array}$ & & \\
\hline -ense & 22 (piedrahitense) & $\mathbf{1 2}$ (villalobense) & $\mathbf{4 2}$ (iscariense) & \\
\hline -eño, -eña & & & $\begin{array}{l}29 \text { (fromisteño, } \\
\text {-eña) }\end{array}$ & \\
\hline -ista & & & & $\mathbf{4}$ (ademarista) \\
\hline
\end{tabular}

Figura 3. Sufijaciones recurrentes: a pesar de que no se puedan establecer unas pautas exactas, resulta interesante observar qué sufijos son más recurrentes en cada uno de los casos.

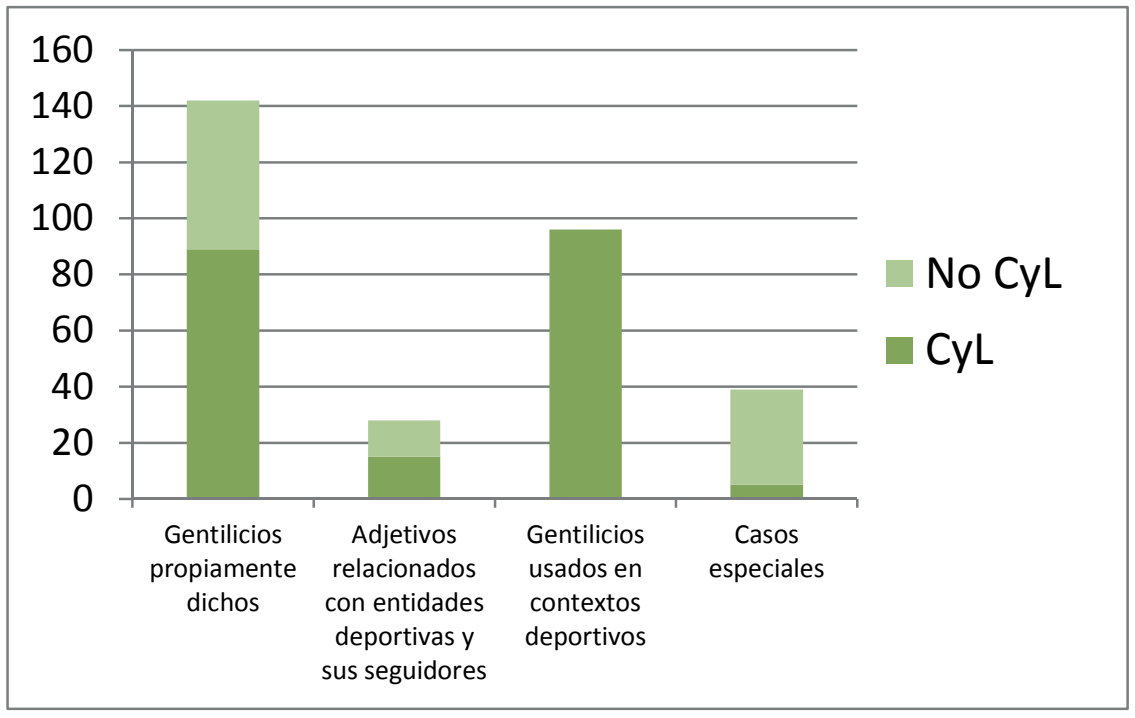

Figura 4. Proporción de unidades referentes a Castilla y León en cada tipo de gentilicio.

Observamos que los datos recogidos plantean una variedad considerable de opciones denominativas, que atienden a criterios morfológicos, pero que también se ven condicionadas por cuestiones más relacionadas con el contexto informativo en el que se encuentran. La innovación y el conservadurismo que estos datos puedan reflejar es, en consecuencia, el resultado de la unión de todos esos factores. Encontramos elementos que respaldan ambas nociones:

\subsection{Razones para el conservadurismo}

De entre las diferentes razones que pueden justificar la preeminencia de un conservadurismo lingüístico en el proceso de creación de neologismos referidos a los gentilicios, podríamos destacar las siguientes: 
- Las múltiples opciones de sufijos derivativos para crear gentilicios permiten una fácil elección de patrones preexistentes, por lo que la creación léxica se limita, en la mayoría de los casos, a procesos derivativos, ya sean de sufijación, en la mayoría de los casos, o prefijación: «Ir andando a la ermita de Hontanares es uno de los pasatiempos preferidos de los riazanos»; «El primer ministro, Vladimir Putin, no descartó que "actuaran los mismos criminales" tanto el lunes en el metropolitano como ayer en la república norcaucásica de Daguestán».

- Observamos que la sección del periódico en la que encontramos cada unidad es otro factor que condiciona su carácter innovador. Así, los gentilicios insertos en contextos derivados de noticias (también diferenciables por su fuente, ya que pueden ser de redacción local o proceder de una agencia de noticias) reflejan patrones formativos clásicos, como los mencionados anteriormente.

- La naturaleza de los gentilicios, en cuanto derivación de un topónimo, es decir, de un apelativo de una realidad prácticamente inmutable durante siglos, dificulta sobremanera la evolución o el neologismo por referirse a realidades de por sí establecidas $\mathrm{y}$, en cierto grado, fosilizadas. La inamovilidad del referente facilita que la unidad escogida para designarlo tienda también a tener ese carácter inmutable. Incluso no son pocos los ejemplos de nombres de localidades o comarcas que varían y cuyos gentilicios permanecen inalterados. En ese caso, el vínculo topónimo-gentilicio pasa a convertirse en localidad-gentilicio, lo que favorece la fosilización y el conservadurismo en la elección denominativa.

En los siguientes ejemplos vemos que tanto adnamantino (relativo a Almazán, Soria) como coyantino (relativo a Valencia de Don Juan, León) no están vinculados con la denominación actual de sendos municipios, sino que, al haber caído en desuso las unidades a partir de las que se formaron, han pasado a estar ligadas directamente a la realidad geográfica a la que hacen referencia, lo que facilita su fosilización y su anclaje en la lengua: «El atleta tuvo una dura resistencia en su paisano, el también adnamantino, Daniel Mateos, al que sólo logró superar en los últimos cien metros de la carrera, y por una diferencia de unos escasos metros»; «La organización del Festival Isla Rock ya lo tiene todo preparado para recibir en Valencia de Don Juan, el próximo fin de semana, tanto a los catorce grupos que componen el intenso cartel de este evento musical como a los cientos de aficionados al buen rock que se esperan en el complejo La Isla de la villa coyantina» ${ }^{9}$.

El hecho de que la totalidad de unidades recogidas en el apartado de gentilicios usados tanto en contextos geográficos como en deportivos sea referentes a Castilla y León supone uno de los principales rasgos de conservadurismo lingüístico inherentes a esta comunidad lingüística que podemos extraer del estudio realizado. La tendencia a suprimir los dobletes geográfico/deportivo y a usar la misma unidad para ambos contextos confirma lo que L. Bauer (1988) ya apuntó a propósito del fracaso del fenómeno de especialización sufijal que él mismo denominó blocking («Blocking does not always

${ }^{9}$ Adnamantino -na se refiere al topónimo latino del actual Almazán, Adnumantia, es decir, «hacia Numancia», ya que la población está situada en la calzada que conducía a esa localidad. Por su parte, coyantino -na hace referencia los topónimos latinos Comeniaca y Castrum Covianca, que evolucionarían en la Alta Edad Media a Cives Quoianka y Coyanza, vigentes hasta el siglo XIII, momento en que se cambian por Valencia de León o Valencia de Campos y finalmente Valencia de don Juan. 
work, [...] it frequently fails to work with the most productive morphological proces$s e s »)$. Si la especialización sufijal se limita, la creación léxica se reduce, lo que favorece, en definitiva, el conservadurismo lingüístico.

La baja proporción de unidades referentes a esta comunidad autónoma en el apartado de «unidades especiales» (sólo un 13\% del total), que son los que más se prestan a la creatividad, también denota una limitación en la neología, ligada en este caso más a la falta de creatividad léxica que a la recurrencia de ciertos patrones formativos. Por otra parte, el alto uso de recursos tipográficos (en un $28 \%$ de las unidades englobadas en este grupo) tales como las comillas, implican que, de alguna manera, se quiere hacer resaltar el carácter anómalo de las unidades empleadas, lo que refuerza la tesis conservadora. «El ex merengue provocó el delirio en la hinchada "rojilla", y los hombres de Juande Ramos bajaron definitivamente los brazos»; "La entrada del capitán "gunner" dejaría fuera a Sergio Busquets».

\subsection{Razones para la innovación}

A pesar de que las razones para pensar en un posible conservadurismo derivado del uso de las unidades estudiadas son numerosas, existen ciertos apuntes de innovación que también consideramos destacables:

- Si los contextos procedentes de noticias mostraban conservadurismo en la elección de gentilicios, existen otras secciones que apuntan a la tendencia contraria:

— Los artículos de opinión: Los textos de los editoriales y demás artículos de opinión suelen estar redactados por autores vinculados de alguna manera al lugar en el que se publican los periódicos, lo que les ser más proclives a la creación y a cierto gusto por la originalidad. Además, no suelen estar regulados por los servicios de correctores de las agencias y sienten más libertad a la hora de nombrar realidades nuevas o en proceso de cambio.

— Deportes: la toma en consideración de los adjetivos relativos a entidades deportivas y a sus seguidores es un signo claro de que esta sección y la realidad a la que hace referencia son un caldo de cultivo para la creación léxica relacionada con elementos geográficos. A pesar de la baja proporción de unidades relacionadas con Castilla y León que encontramos en el apartado de deportivos especiales, y a la que ya hemos hecho referencia como hipotética marca de conservadurismo, las pocas unidades allí encontradas marcan la pauta de la que será una de las principales vías de innovación léxica para los gentilicios castellanoleoneses en el futuro: la de la asociación de realidades geográficas con otras de otros tipos (marcas comerciales, colores de la equipación, aspectos particulares de la idiosincrasia de cada lugar) para dar como resultado nuevas unidades de marcado carácter local. La consecuencia de la utilización de esa vía de creación neológica es que los mecanismos usados se diversificarían, dejando de limitarse al uso de patrones derivativos y adoptando nuevos recursos, como el préstamo interlingüístico, la neología semántica o la variación. Un caso real (aunque no recogido en nuestro corpus) es el neologismo semántico perfumeras, aplicado a las jugadoras del equipo femenino de baloncesto de Salamanca, patrocinado por una cadena de droguerías y perfumerías. Sí está recogido el caso de ademarista, derivado del acrónimo Ademar (de Asociación De Ex-alumnos MARistas), como muestra apenas testimonial de la exigua formación neológica en la prensa castellano y leonesa, o el adjetivo tormesino, -na, en origen 
relativo al río Tormes, de cuyo uso para designar a los seguidores de la desaparecida Unión Deportiva Salamanca hay constancia en nuestro corpus.

- Composición ad hoc con guión contextos no deportivos: al hablar de los gentilicios encontrados en contextos sin relación con el ámbito deportivo, ya hicimos referencia a este recurso formativo como recurrente. A pesar de que su importancia es secundaria, ya que en la mayoría de los casos la validez de la unidad formada se limita al contexto concreto en el que aparece (de ahí que la denominemos $a d$ hoc), nos parece interesante reseñarlo, no ya por las unidades que se producen gracias a él, sino por la propia recurrencia del recurso en sí, en detrimento de opciones más conservadoras, como hubieran sido la aposición o el uso de la conjunción copulativa. En estos dos últimos casos no habrían tenido lugar cambios morfológicos que sí que provoca el uso de guiones, lo que habría limitado aún más la creación léxica. Por ejemplo, la elección de «albano-kosovar» en el ejemplo «Volvería a tratarse de un ajuste de cuentas entre bandas de albano-kosovares» y no de la opción "albanesas y kosovares», implica que, en pos de la economía lingüística, se producen cambios morfológicos que conllevan cierta innovación.

\section{CONCLUSIONES}

A juzgar por la manera en que se definen en distintos diccionarios, los gentilicios y las demás unidades recogidas en este estudio juegan en su caracterización semántica con elementos de diverso tipo. Por un lado, elementos geográficos (físicos) y por otro, elementos relacionados con la nacionalidad y la raza (sociales e históricos).

Además, la relación de su configuración formal con la realidad a la que hacen referencia presenta una idiosincrasia particular, que se resume en tres puntos: la dificultad en la sistematización de sus procesos derivativos; la dispersión, provocada en gran medida por factores extralingüísticos, no ya en un mismo paradigma formativo, sino para un mismo topónimo y por último, la existencia de dos (o más) gentilicios referidos al mismo topónimo que conviven en un mismo momento, aunque con valores socioculturales o pragmáticos diferentes. Podemos encontrar un reflejo claro de las dificultades que entrañan estas tres cuestiones tanto si abordamos el estudio de los gentilicios desde una clave diacrónica como si lo hacemos desde una sincrónica.

Los datos obtenidos en el estudio presentado, junto con la reflexión teórica en torno a la problemática de la caracterización de los gentilicios, confirman la idea inicial de diversidad y complejidad y plantean un escenario concreto (el castellanoleonés) de gran riqueza y variedad de recursos para la creación léxica, en la que entran en juego factores de muy diversa índole. Sin embargo, esa pluralidad, que a priori podría parecer un buen caldo de cultivo para la neología, presenta una serie de parámetros que finalmente no confirman esa regeneración, sino más bien lo contrario. A pesar del mencionado peso del ámbito deportivo, que actúa como principal acicate para la innovación, y de casos aislados que demuestran que la factibilidad de interesantes procesos de creación léxica, resulta significativa la alta prevalencia de gentilicios relacionados con Castilla y León que pueden usarse en contextos geográficos y deportivos, y, al mismo tiempo, el bajo índice de unidades relativas a esa comunidad en el apartado de unidades especiales, tan heterogéneo y rico en soluciones denominativas. Todos estos factores nos llevan a inclinarnos por la idea de que el uso que se da de los gentilicios y de las unidades relacionadas con realidades geográficas en la prensa castellanoleonesa 
puede considerarse como marca de conservadurismo lingüístico para esta comunidad, lo que no deja de ser una paradoja, si contrastamos este hecho con la variedad creativa manifiesta para este tipo de unidades en español.

\section{REFERENCIAS BIBLIOGRÁFICAS}

BAUER, Laurie (1988): Introducing Linguistic Morphology, Edinburgh, Edinburgh University Press.

CELDRÁn, Pancracio (2002): Diccionario de topónimos y sus gentilicios, Madrid, EspasaCalpe.

FERRECCIO PODESTÁ, Mario (1993): El gentilicio: identificación de una categoría onomasiológica, Santiago de Chile, Universidad de Santiago de Chile.

(2006): «Una singularidad en la formación de los gentilicios: irradiación, cognados y afines», Onomázein, 1, pp. 177-189.

GARCÍA PADRÓN, Dolores (2012): «Tipos de alogentilicios y su descripción en los diccionarios académicos españoles», en Avances de Lexicografia Hispánica, Tarragona, Universitat Rovira i Virgili, I, pp. 147-155.

García Palacios, Joaquín, J. Agustín ToriJano y Miguel SÁnchez IbáÑEz (2011): «Cuando los cuellaranos usaron los blogs y las vuvucelas: neologismos en una comunidad lingüística ¿conservadora?», en Actas del Congreso Internacional de Neología (CINEO), São Paulo (en prensa).

Gómez CAPUZ, Juan (1998): El préstamo lingüistico. Concepto, problemas y métodos, Valencia, Universitat de Valéncia.

GUILBERT, Louis (1975): La créativité lexicale, París, Larousse.

LÁZARO CARRETER, Fernando (2008): Diccionario de términos filológicos, Madrid, Gredos.

Moliner, María (2008): Diccionario de uso del español, Madrid, Gredos.

Pena SeIJAS, Jesús (1999): «Partes de la morfología. Las unidades del análisis morfológico», en Ignacio Bosque y Violeta Demonte, dir., Gramática descriptiva de la Lengua Española, Madrid, Espasa-Real Academia Española, pp. 4305-4366.

PÉrez Vigaray, Juan Manuel y Juana HerRera SANTANA (2013): «El artículo lexicográfico de los sufijos con acepción gentilicia en español: su tratamiento en el DRAE-01», en prensa.

Quintiliano, Marco Fabio (1997): Institutio Oratoria, trad. de Alfonso Ortega Carmona, Libro XII, Sobre la formación del orador, Salamanca, Universidad Pontificia de Salamanca.

RAINER, Franz (1999): «La derivación adjetival», en en Ignacio Bosque y Violeta Demonte, dir., Gramática descriptiva de la Lengua Española, Madrid, Espasa-Real Academia Española, pp. 4595-4644.

RIO-TORTO, Graça Maria (1998): Morfologia derivacional: teoria e aplicação ao portugués, Porto, Porto Editora, Colecção Linguística, 12.

(2008): «Mudança genolexical: teoria e realidade», Revista de Estudos Linguísticos da Universidade do Porto, 3, pp. 223-240.

SANTANA SuÁREZ, Octavio (2003): «Relaciones morfoléxicas sufijales del español», Procesamiento del Lenguaje Natural, 30, pp. 1-73.

SANTANO Y LEÓN, Daniel (1981): Diccionario de gentilicios y topónimos, Madrid, Paraninfo. 
De la TORRe Aparicio, Tomás (2006): Gentilicios españoles, Madrid, Visión Net.

TORRes CABrera, Genoveva (2003): «Sobre toponomástica», PhilologicaCanariensia, 8-

9, pp. 191-206.

- (2007): «Algunas puntualizaciones en torno a la formación de palabras en español», Philologica Canariensia, 12-13, pp. 49-66.

VARIOS (2003): Diccionario de uso del español de América y de España, Madrid, VOX.

VARIOS (2003): Diccionario CLAVE, Madrid, SM.

En formato electrónico [consultadas por última vez el 15 de mayo de 2013].

Glosario Electrónico de Términos Lingüísticos:

http://www.sil.org/mexico/ling/glosario/E005ae-Glosario.htm

Grupo GentiDB: http://gentidb.saii.ull.es/actividades/

http://www.guiapraticodeespanhol.com.br/2010/05/os-paises-e-as-nacionalidades-em.html

http://www.portaldalinguaportuguesa.org/index.php?action=toponyms

http://www.shertonenglish.com/resources/es/adjectives/adjectives-proper.php. 